\title{
RE-FRAMING EXPLOITATION CREEP TO FIGHT HUMAN TRAFFICKING: A RESPONSE TO JANIE CHUANG
}

\author{
Clifford Bob*
}

Janie Chuang ${ }^{1}$ discusses important shifts in the way that American policy makers and activists have defined and fought human trafficking. As she shows, key aspects of the 2000 UN Protocol's definition of trafficking have been whiplashed by changing political winds emanating from the Bush and Obama administrations. In the Bush years, a strange bedfellows network of feminists, evangelicals, and neo-conservatives directed American trafficking policy primarily toward sexual exploitation, pushing for prohibitions not only on forced but also on voluntary prostitution. Other types of trafficking were neglected. The Obama administration and its own set of civil society associates gusted other ways. Among other moves, it reduced the focus on sex, dropped the view that voluntary prostitution constituted trafficking, enlarged the trafficking concept to include all forced labor (whether or not involving movement), and rebranded the expansive new notion as slavery.

For Chuang, this "exploitation creep" on trafficking has caused problems but also offers opportunities. On the downside, despite the public outrage it created, identifying trafficking with sex and slavery may not have increased "overall capacity to address the full continuum of forced labor and trafficking practices." On the other hand, Chuang urges labor rights activists to seize on the newly expanded concept— to exploit exploitation creep themselves. After all, trafficking has become a "hot" issue through its rebranding. Large amounts of energy and money have entered the field, epitomized by impassioned undergraduates and deep-pocketed philanthropists. If the labor rights movement can convince some of these new actors (especially the deeppocketed ones) to push for strengthening and enforcement of labor laws, they may be able to attack the underlying issues that give rise to trafficking. Prevention can enjoy equal status with punishment. Weak laws, halfhearted enforcement, or perhaps even the "neo-liberal" economic system can replace criminal traffickers as the movement's bête noir.

For analysts of politico-legal change, Chuang's article is an excellent case study. Particularly useful is its finegrained account of how competing political networks shifted the meaning of trafficking - and the problematic results of those shifts for those being trafficked, as well as others suffering various forms of labor-related exploitation. Chuang's suggestion that labor rights activists seize the initiative is also intriguing. For socio-legal scholars, Chuang's article opens the door to important questions: Is "exploitation creep" unique to the trafficking realm? If not, what are the broader mechanisms, and what are their implications for legal analysis and practice? What can we learn from widening the lens that might help labor activists in the trafficking area? I argue that "exploitation creep" is common in many realms even where legal doctrine might seem to be relatively

* Professor of political science and Raymond J. Kelley Endowed Chair in International Relations at Duquesne University. He holds a J.D. from New York University School of Law and a Ph.D. from the Massachusetts Institute of Technology. His books include THE GLOBAL RIGHT WING AND THE CLASH OF WORLD POLITICS (Cambridge University Press, 2012) and THE MARKETING OF REBELLION: INSURGENTS, MEDIA, AND INTERNATIONAL ACTIVISM (Cambridge, 2005).

Originally published online 11 June 2015.

${ }^{1}$ Janie Chuang, Exploitation Creep and the Unmaking of Human Trafficking Law, 108 AJIL 610 (2014). 
stable — and all the more so in international policymaking, where stability is minimal. To contribute to theory development and political change in this area, however, I urge scholars to use existing terminology related to the well-known concept of "framing," as used in sociology, communications, and political science. I briefly discuss various framing mechanisms and conclude by examining their implications for analysts and activists in the human trafficking realm.

To begin, let me elaborate on my reservations about the term "exploitation creep." They are twofold: first, the term creates possible confusion with the quite distinct concept of "mission creep"; second, as outlined above, terms already common in the scholarly literature, some used by Chuang in the article, more clearly differentiate and describe the ongoing conflict over human trafficking's meaning. Mission creep is well known as a process by which organizations slowly and often secretly expand narrow grants of discretion, usually with disastrous results. In the Vietnam War, U.S. involvement gradually shifted from training missions to full-scale war, accelerated by the exaggerated Tonkin Gulf incident. In Libya in 2011, NATO forces broke through UN Security Council Resolution 1973's call for civilian protection and engaged in militarized regime change. Today President Obama has expanded the term "al Qaeda" in the 2001 Congressional Authorization for the Use of Military Force to fight the Islamic State, a group that did not exist in 2001 and that views al Qaeda as its sworn enemy. And at the World Bank, a mission that began decades ago with a narrow focus on economic development of poor countries has ballooned into all manner of social, legal, environmental, and other goals. What these and numerous other cases of creep have in common is that they are manifestations of the principal-agent problem: An agent oversteps the discretion granted it by a principal, usually by expanding but also by contracting or distorting the goals sought by the principal or the means designated to achieve them. Agents may do so for venal reasons - personal or institutional gain—but also for principled ones, a sincere belief in the necessity of violating the grant of discretion to better achieve the goal. Creep may even begin inadvertently, with unnoticed, incremental changes that ratchet a mission into novel goals or tactics. What is characteristic of mission creep, however, is that the agent illegitimately or illegally exceeds the discretion granted by the principal.

By contrast, most of what Chuang describes are cases in which various principals seek to reshape the scope and meaning of the ill-defined and politically fraught "human trafficking" concept. Notwithstanding the UN Protocol, no one has ownership over the concept, although some entities seem to seek it. Some may do so for their own benefit or to support a broader ideological agenda. For the most part they appear to be doing so because of their own conception of what would benefit those who are trafficked - even if in reality that may not be the case. In Chuang's story, there appear to be few agents (within the meaning of principal-agent theory). As a result, there is little illegitimate, let alone illegal, in her story, and most of the action occurred fairly openly. "Exploitation creep" may be one way to describe all this, and Professor Chuang is of course free to choose her terminology. But because of the sharp contrasts from the seemingly allied concept of mission creep, there are better ways to describe what has happened.

This is all the more so because what Professor Chuang so ably discusses in the human trafficking area has been analyzed for decades by other scholars under the broad concept of "framing." As Robert Entman defined it in a 1993 literature review, ${ }^{2}$ framing is the process by which political actors "select some aspects of a perceived reality and make them more salient in a communicating text, in such a way as to promote a particular problem definition, causal interpretation, moral evaluation, and/or treatment recommendation for the item described."

Professor Chuang's definition of exploitation creep- "efforts to expand previously narrow legal categories - at least in terms of rhetoric and policy, but in some cases also in hard law-in a strategic bid to subject a broader range of practices to a greater amount of public opprobrium" - fits easily within this definition. Placing it in this well-trodden conceptual terrain not only reduces unnecessary conceptual proliferation but also

2 Robert M. Entman, Framing: Toward Clarification of a Fractured Paradigm, 43 J. COMM. 51 (1993). 
affords access to a number of ancillary concepts. These should help scholars illuminate the processes involved and may help activists identify useful strategies for achieving their ends. David Snow and collaborators ${ }^{3}$ have identified a number of these: "transformation," reshaping or redefining an existing frame; "amplification," enlarging and strengthening it; and "bridging," linking it to a different frame. Other scholars such as Richard Price 4 speak of "grafting" a new norm onto an existing one, using various persuasive techniques.

Numerous books and articles have examined similar re-framing processes in a variety of issue areas, ranging from new international conventions such as the Landmines Treaty and Rome Statute of the International Criminal Court to state and nongovernmental interventions into conflict zones. ${ }^{5}$

What these accounts typically share, as in the case of Professor Chuang's article, is the strategic attempt by particular actors to use existing legal doctrine, policy prescriptions, or normative understandings to achieve goals. In some cases, these goals may not be stated specifically in the text of a policy or law-or may not even have been contemplated by those who initially developed the concepts. The trafficking/forced labor/slavery conflation exemplifies this. As another example, recent attempts at the international level to promote new rights such as gay rights often involve re-framing of broad language concerning human rights or women's rights, which was developed at a time when homosexuality itself was considered immoral in most societies. ${ }^{6}$ Of course, framing processes are seldom sufficient to achieve political goals. (Nor are other well-known rhetorical strategies such as "naming and shaming.") Resources and power, often provided by social movements or political parties, are critical. As Chuang tells it, this is a major reason that the redefinition of human trafficking succeeded: two U.S. administrations were behind it, albeit administrations deeply influenced by and intertwined with civil society networks and political parties. They re-framed the problem, proposed new solutions, activated political institutions, set agendas, and persuaded broader audiences. (Of course, as Chuang rightly notes, this rhetorical and political "success" says nothing about whether their moves have helped solve the underlying problem of trafficking.) By contrast, in other cases where such power was not present those promoting an agenda have had much greater difficulty even in shifting the terms of debate.

Notably, as well, although the trafficking case involves governmental forces in alliance with nongovernmental organizations, both the Bush and Obama administrations faced opposition in their re-framing efforts. Indeed, the evangelical network linked to the Bush administration and the human rights network close to the Obama administration were often at odds with one another in each period. In other policy areas, resistance has frequently prevented networks advocating change from achieving their goals. On most issues, both at national and international levels, conflicting networks composed of loose agglomerations of states and civil society actors compete against one another to influence law and policy. In doing so, they use the rhetorical strategies noted above to advance their causes. At the same time, as the scholarly literature has shown, ${ }^{7}$ they deploy a variety of negative strategies, both rhetorical and active, to deflect, distort, and block their rivals. For instance, even as one side advances a new frame, the other seeks to smash it. One side's frame extension faces off against another's frame contraction. Frame bridging and grafting are matched by efforts at frame severing. As one network seeks to set the agenda, its rival seeks to unset it or to activate friendlier institutions. The construction of problems and favored policy solutions is typically met by efforts to construct a rival problem/solution-and to deconstruct the foe's problem and problematize its preferred solution. In Chuang's article, arguments against the Bush administration's focus on sexual exploitation and against the Obama administration's modern-day slavery

\footnotetext{
${ }^{3}$ David A. Snow et al., Frame Alignment Processes, Micromobilization, and Movement Participation, 51 AM. Soc. Rev. 464 (1986).

${ }^{4}$ Richard Price, Reversing the Gun Sights: Transnational Civil Society Targets Land Mines, 52 INT'L OrG. 613 (1998).

${ }^{5}$ Clifford Bob, The Marketing of Rebellion: Insurgents, Media, and International Activism (2005).

${ }^{6}$ Clifford Bob, The International Struggle For New Human Rights (2008).

${ }^{7}$ Clifford Bob, The Global Right Wing and the Clash of World Politics (2012).
} 
abolitionism represent examples of such complex political processes, involving both affirmative and negative framing as well as other persuasion tactics. Other examples are legion, including conflicts over national and international policies on climate change, small arms control, sexual rights, and many other issues. ${ }^{8}$

There are several lessons of the broad literature surrounding the framing concept. ${ }^{9}$ For one thing, it is relatively easy to stigmatize an identifiable individual or a situation in which there is a short causal chain and bodily harm to vulnerable individuals. This is one reason that individual traffickers have been successfully placed into judicial crosshairs and why the emotive concept of slavery has gained attention. By contrast, it is harder to frame around prevention or to demonize broadly defined economic forces. ${ }^{10}$ Specific corporations represent an easier target, but the length of the causal chain between vaguely written labor laws, loose enforcement, and exploitation can be problematic. With this in mind, targeting corporations that can be shown to have used forced labor makes sense, and could in some cases serve as a wedge to encourage broader legal reform. Against the inevitable and already-existing pushback from groups that benefit from the existing system—as Chuang documents in the proposed legislative reforms to the J-1 Visitor Exchange Program-activists might consider using some of the specific persuasion tactics noted above. As Chuang clearly shows, change will not be easy. This is all the more so if one moves beyond the United States itself. Confidence that even a superpower can impose its view of these problems on other countries seems misplaced. Frames and campaigns that work in one state often have little traction in others. But using some of the lessons learned in other persuasion campaigns, ${ }^{11}$ labor activists may stand a higher chance of reaching their important goals both in the United States and internationally.

\footnotetext{
${ }^{8} \underline{I d}$.

9 Margaret E. Keck \& Kathryn SikKink, ACtivists Beyond Borders: AdvocaCy Networks in InTERnational Politics (1998).

${ }^{10}$ Keneth Roth, Defending Economic, Social and Cultural Rights: Practical Issues Faced by and International Human Rights Organization, 26 Hum. RTS. Q. 63 (2004).

11 Jarol B. Manheim, Strategy in Information and Influence Campaigns: How Policy Advocates, Social Movements, INSURGENT GROUPS, CORPORATIONS, GOVERNMENTS AND OTHERS GET WHAT THEY WANT (2011).
} 